\title{
Water-carbon coupling modeling of summer maize at the leaf and canopy scales
}

\author{
ZHANG BaoZhong ${ }^{1,2,3}$, LIU Yu ${ }^{1,2}$, XU Di $^{1,2^{*}}$, CAI JiaBing ${ }^{1,2} \&$ WEI Zheng ${ }^{1,2}$ \\ ${ }^{1}$ State Key Laboratory of Simulation and Regulation of Water Cycle in River Basin, China Institute of Water Resources and Hydropower \\ Research, Beijing 100038, China; \\ ${ }^{2}$ National Center of Efficient Irrigation Engineering and Technology Research-Beijing, Beijing 100048, China; \\ ${ }^{3}$ Department of Soil and Water Sciences, College of Resources and Environment, China Agricultural University, Beijing 100193, China
}

Received August 22, 2012; accepted November 29, 2012; published online February 27, 2013

Transpiration and photosynthesis are two closely related and intercoupled processes that dominate the physiological activities and yield of crops. Therefore, there is a need to study water-carbon coupling modeling at various scales to increase water use efficiency (WUE). Using a summer maize field in North China as an example, the variations in leaf and canopy photosynthesis and transpiration (or evapotranspiration) were analyzed. The synthetic model of photosynthesis-transpiration based on stomatal behavior (SMPT-SB) was then calibrated and validated at the two scales. The leaf photosynthesis and transpiration, as well as the canopy photosynthesis and evapotranspiration, have a consistent diurnal trend. However, the canopy evapotranspiration is affected more by topsoil moisture content. The regression coefficient between leaf photosynthesis, transpiration, and WUE estimated by the SMPT-SB and the measured values was found to approach 1, with a coefficient of determination of more than 0.74 . The relative error between the two sets of values is less than $11 \%$. Therefore, the SMPT-SB could express fairly well leaf photosynthesis, transpiration, and WUE. The estimated canopy-scale photosynthesis by the SMPT-SB is also in good agreement with the measured values. However, this model underestimates the canopy evapotranspiration when the topsoil has high moisture content and therefore overestimates, to a certain extent, the canopy WUE.

photosynthesis, transpiration, water use efficiency, SMPT-SB, stomatal conductance, maize

Citation: Zhang B Z, Liu Y, Xu D, et al. Water-carbon coupling modeling of summer maize at the leaf and canopy scales. Chin Sci Bull, 2013, 58: 3361-3370, doi: $10.1007 / \mathrm{s} 11434-012-5630-0$

Farmland water cycle and carbon cycle are closely related and intercoupled ecological processes that affect the physiological activities and yield of plants $[1,2]$. Hence, the coupling of water and carbon cycles should be studied to improve water use efficiency (WUE). And the study of water-carbon coupling at the leaf and canopy scales could provide an insight into the physio-ecological mechanism of stomatal control during water and carbon cycle processes, reveal the scale effect and intrinsic link of water-carbon coupling and serve as a basis in establishing a coordinated and unified water-carbon coupling model and WUE estimation method.

*Corresponding author (email: xudi@iwhr.com)
At present, evapotranspiration estimation models, including the Penman-Monteith (P-M) model [3,4], Shuttleworth-Wallace model [5], and other multilayer models [6,7], are mainly based on both energy and water equilibrium principles. Numerous plant photosynthesis models were also reported, such as the leaf biochemical model suggested by Farquar and Von Caemmerer in 1982, which expresses the photosynthetic rate as a function of intercellular carbon dioxide $\left(\mathrm{CO}_{2}\right)$ concentration, light quantum flux density, and temperature [8]. And the model is extensively used because of its few parameters [9-11]. Canopy-scale photosynthesis models are generally developed by expanding leaf photosynthesis models at the canopy scale, and they can be categorized into single-layer model $[12,13]$, two-layer mod- 
el [14], and multilayer model [15].

Numerous observation tests indicate that leaf photosynthesis and transpiration show homoplasy with respect to various environmental factors. And the role of stomata in regulating vapor and $\mathrm{CO}_{2}$ exchange between plants and the atmosphere has been identified and confirmed. However, the relationship between water and carbon fluxes is not a simple linear relation. Although stomata are the major channels of transpiration and photosynthesis, they have a slightly different response to these two processes. For instance, at a given transpiration amount, leaves regulate stomata initiatively to maximize the photosynthetic rate [16-18]. Thus, Leuning [18] and Collatz et al. [19] introduced the idea of coupling photosynthesis, transpiration, and heat balance. Ball developed a coupling model [20,21] of leaf stomatal conductance, net photosynthesis rate, and environmental factors, which has been widely applied at the leaf, canopy, water basin, and global scales [22-24]. Yu and Wang constructed a complete physiological model [25] consisting of leaf photosynthesis, transpiration, and stomatal conductance sub-models by considering boundary layer conductance. Moreover, large-scale water-carbon coupling models primarily include FOREST-BGC [26], AVIM [27], SiB2 [28], IBIS [29], and BEPS [30,31].

These models provide substantial information on the coupling mechanism of photosynthesis and transpiration. However, their complexity limits their extensive applications. Hence, $\mathrm{Yu}$ et al. [32,34] introduced $\mathrm{CO}_{2}$ internal conductance based on the physiological mechanism of photosynthesis and transpiration controlled by stomatal behavior, and developed a synthetic model of photosynthesis-transpiration (SMPT-SB) [32,33]. The SMPT-SB was found to be useful in maize, soybean, and tree leaf scales. Ren et al. [35] also constructed canopy-scale SMPT-SB of broad-leaved forest in Changbai Mountain and revealed good results. However, the simultaneous application of this model at the leaf and canopy scales has not been reported.

Several studies on water and carbon fluxes have been carried out. However, a joint analysis of multi-scale watercarbon coupling relation $[2,36]$ is rarely conducted. Therefore, the present study aims to analyze the variations of photosynthesis and transpiration (or evapotranspiration) rates at the leaf and canopy scales, calibrate and validate the water-carbon coupling SMPT-SB, and estimate the WUE. It also aims to analyze the model's influencing factors.

\section{Water-carbon coupling SMPT-SB}

\subsection{Water-carbon coupling model at the leaf scale}

(i) Transpiration model. Leaf water $\left(\mathrm{H}_{2} \mathrm{O}\right)$ flux is a function of the atmosphere, plant, and other factors described below [33]:

$$
T_{-L}=\frac{W_{i-L}-W_{a-L}}{1 / g_{b w-L}+1 / g_{s w-L}},
$$

where $T_{-L}$ is the leaf transpiration rate, mmol m ${ }^{-2} \mathrm{~s}^{-1} ; W_{i-L}$ and $W_{a-L}$ are the mole fraction of water vapor in leaf stomata and in the atmosphere, respectively, mmol mol${ }^{-1}$; and $g_{b w-L}$ and $g_{s w-L}$ are the conductance to $\mathrm{H}_{2} \mathrm{O}$ diffusion through the leaf boundary layer and leaf stomata, respectively, $\mathrm{mol} \mathrm{m}^{-2} \mathrm{~s}^{-1}$.

The stomatal conductance is estimated by the Ball model developed by Leuning et al. [33,37]:

$$
g_{s w-L}=g_{0-L}+a_{1-L} A_{-L} R H_{-L} /\left(C_{s-L}-\Gamma_{-L}\right),
$$

where $A_{-L}$ is the leaf photosynthetic rate, $\mu \mathrm{mol} \mathrm{m} \mathrm{m}^{-2} \mathrm{~s}^{-1} ; g_{0-L}$ is the residual stomatal conductance (as $A_{-L} \rightarrow 0$ when light quantum flux density $\rightarrow 0$ ), mol m $\mathrm{m}^{-2} \mathrm{~s}^{-1} ; C_{s-L}$ is the ambient $\mathrm{CO}_{2}$ concentration at the leaf surface, $\mu \mathrm{mol} \mathrm{m} \mathrm{m}^{-2} \mathrm{~s}^{-1} ; \Gamma_{-L}$ is the $\mathrm{CO}_{2}$ compensation point with dark respiration, $\mu \mathrm{mol} \mathrm{m} \mathrm{m}^{-2} \mathrm{~s}^{-1} ; R H_{-L}$ is the relative humidity at the leaf surface; and $a_{1-L}$ is a coefficient.

(ii) Photosynthesis model. Considering the effect of biochemical and photochemical processes in the boundary layer, stoma, and mesophyll, then the photosynthesis rate model may be expressed as follows [33]:

$$
A_{-L}=\frac{C_{a-L}-\Gamma_{*-L}}{1 / g_{b c-L}+1 / g_{s c-L}+1 / g_{i c-L}},
$$

where $C_{a-L}$ is the ambient $\mathrm{CO}_{2}$ concentration, $\mu \mathrm{mol} \mathrm{mol}{ }^{-1}$; $\Gamma_{*-L}$ is the $\mathrm{CO}_{2}$ compensation point without dark respiration, $\mu \mathrm{mol} \mathrm{mol}{ }^{-1} ; g_{b c-L}$ and $g_{s c-L}$ are the conductance of the leaf boundary layer and leaf stomata to $\mathrm{CO}_{2}$, respectively, $\mathrm{mol} \mathrm{m} \mathrm{m}^{-2} \mathrm{~s}^{-1}$; and $g_{i c-L}$ is the leaf "internal" conductance, mol m $\mathrm{m}^{-2} \mathrm{~s}^{-1}$.

Yu et al. [33] stated that the "internal" conductance may be expressed by the following formula without any environmental stress:

$$
g_{\text {ic-L }}=M+N Q_{p},
$$

where $Q_{p}$ is the light quantum flux density, $\mu \mathrm{mol} \mathrm{m} \mathrm{m}^{-2} \mathrm{~s}^{-1}$; and $M$ and $N$ are coefficients.

(iii) Photosynthesis-transpiration coupling model. In the field experiment, $\Gamma_{*_{-}}$and $\Gamma_{-L}$ are approximately equal, and $g_{0-L}$ could generally be ignored when considering the diffusion of $\mathrm{CO}_{2}$ through stomata. Assuming that $g_{s w-L}=$ $1.56 g_{s c-L}$ and $g_{b w-L}=1.37 g_{b c-L}$, then the leaf photosynthesis and transpiration rates may be expressed as follows [33]:

$$
\begin{gathered}
A_{-L}=\frac{\left(C_{a-L}-\Gamma_{*-L}\right)\left[1-1.56 /\left(a_{1-L} R H_{-L}\right)\right]}{1.37 / g_{b w-L}+1 / g_{i c-L}}, \\
T_{-L}=\frac{W_{i-L}-W_{a-L}}{\frac{1}{g_{b w-L}}+\frac{1}{g_{0-L}+\frac{\left(a_{1-L} R H_{-L}-1.56\right)}{\left(1.37 / g_{b w-L}+1 / g_{i c-L}\right)}}} .
\end{gathered}
$$

(iv) WUE model. With eqs. (5) and (6) simultaneously in place, the WUE model can be derived as follows: 


$$
\begin{aligned}
\mathrm{WUE}_{-L}= & \frac{A_{-L}}{T_{-L}}=\frac{\left(C_{a-L}-\Gamma_{*-L}\right)\left[1-\frac{1.56}{\left(a_{1-L} R H_{-L}\right)}\right]}{W_{i-L}-W_{a-L}} K_{r-L}, \\
K_{r-L}= & \frac{1 / g_{b w-L}}{1.37 / g_{b w-L}+1 / g_{i c-L}} \\
& +\frac{1}{g_{0-L}\left(\frac{1.37}{g_{b w-L}}+\frac{1}{g_{i c-L}}\right)+a_{1-L} R H_{-L}-1.56},
\end{aligned}
$$

where WUE $_{-L}$ is the WUE at the leaf scale, $\mu \mathrm{mol} \mathrm{mmol}^{-1}$.

\subsection{Water-carbon coupling model at the canopy scale}

When the leaf area index (LAI) is more than 3 , the $\mathrm{CO}_{2}$ rate of the water-carbon coupling model at the canopy scale can be estimated using the following formula [35]:

$$
A_{-C}=\frac{\left(C_{r-C}-\Gamma_{*-C}\right)\left[1-1.56 /\left(a_{1-C} R H_{-C}\right)\right]}{1.37 / g_{b w-C}+1 / g_{i c-C}+1 / g_{a-C}},
$$

where $A_{-C}$ is the photosynthetic rate at the canopy scale, $\mu \mathrm{mol} \mathrm{m} \mathrm{m}^{-2} \mathrm{~s}^{-1} ; C_{r-C}$ is the $\mathrm{CO}_{2}$ concentration in the atmosphere at the reference height, $\mu \mathrm{mol} \mathrm{mol}{ }^{-1} ; \Gamma_{*-C}$ is the $\mathrm{CO}_{2}$ compensation point of a virtual leaf without dark respiration, $\mu \mathrm{mol} \mathrm{mol}{ }^{-1} ; g_{b w-C}$ is the conductance to $\mathrm{H}_{2} \mathrm{O}$ diffusion through the virtual leaf boundary layer at the canopy scale, mol m $\mathrm{m}^{-2} \mathrm{~s}^{-1} ; g_{i c-C}$ is the "internal" conductance of the virtual leaf, $\mathrm{mol} \mathrm{m}^{-2} \mathrm{~s}^{-1} ; g_{a-C}$ is the aerodynamic conductance, mol $\mathrm{m}^{-2} \mathrm{~s}^{-1} ; R H_{-C}$ is the relative humidity of the air around the virtual leaf; and $a_{1-C}$ is a coefficient.

The transpiration rate at the canopy scale can be expressed as follows:

$$
E T_{-C}=\frac{1}{\frac{1}{g_{a-C}}+\frac{1}{g_{b w-C}}+\frac{W_{i-C}-W_{r-C}}{g_{0-C}+\frac{a_{1-C} R H_{-C}-1.56}{\frac{1.37}{g_{b w-C}}+\frac{1}{g_{i c-C}}+\frac{1}{g_{a-C}}}}},
$$

where $E T_{-C}$ is the evapotranspiration rate at the canopy scale, $\mathrm{mmol} \mathrm{m}^{-2} \mathrm{~s}^{-1} ; W_{i-C}$ and $W_{r-C}$ are the mole fraction of water vapor in the virtual leaf stomata and in the atmosphere at the reference height, respectively, mmol mol ${ }^{-1}$; and $g_{0-L}$ is the residual stomatal conductance of the virtual leaf (as $A_{-C} \rightarrow 0$ when light quantum flux density $\rightarrow 0$ ), $\mathrm{mol} \mathrm{m} \mathrm{m}^{-2}$.

The "internal" conductance at the canopy scale is the integral of light quantum flux density over the canopy:

$$
\begin{aligned}
g_{i c-C} & =\int_{Q_{b}}^{Q_{t}}\left(M+N Q_{p}\right) \\
& =M Q_{t}\left(1-\mathrm{e}^{-\varepsilon L A I}\right)+\frac{1}{2} N Q_{t}^{2}\left(1-\mathrm{e}^{-2 \varepsilon L A I}\right),
\end{aligned}
$$

where $Q_{t}$ and $Q_{b}$ are the light quantum flux densities at the

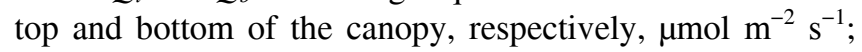
$\varepsilon$ is the coefficient of extinction; and LAI is the leaf area index.

With eqs. (9) and (10) simultaneously in place, the WUE at the canopy scale was derived using the following formula:

$$
W U E_{-C}=\frac{A_{-C}}{E T_{-C}}=\frac{\left(C_{r-C}-\Gamma_{*-C}\right)\left[1-\frac{1.56}{\left(a_{1-C} R H_{-C}\right)}\right]}{W_{i-C}-W_{r-C}} K_{r-C},
$$

$$
\begin{aligned}
K_{r-C}= & \frac{1 / g_{a-C}+1 / g_{b w-C}}{1.37 / g_{b w-C}+1 / g_{i c-C}+1 / g_{a-C}} \\
& +\frac{1}{g_{0-C}\left(\frac{1.37}{g_{b w-C}}+\frac{1}{g_{i c-C}}+\frac{1}{g_{a-C}}\right)+a_{1-C} R H_{-C}-1.56}
\end{aligned}
$$

where WUE $_{-C}$ is the WUE at the canopy scale, $\mu \mathrm{mol}$ $\mathrm{mmol}^{-1}$. Other model parameters can be found in $[33,35]$.

\subsection{Model evaluation indices}

The effect of the model is primarily evaluated using the coefficient of regression $(b)$, the coefficient of determination $\left(R^{2}\right)$, root-mean-square error (RMSE), mean absolute error (MAE), coefficient of consistency $\left(d_{I A}\right)$, and mean. Their calculation can be found in the literature [38].

\section{Materials and methods}

\subsection{Experimental site}

The field experiment was conducted during the growth stage of summer maize from 2008 to 2010 (June to October) at the Irrigation Experiment Station, Institute of Water Resources and Hydropower Research (IWHR), Beijing, China $\left(39^{\circ} 37^{\prime} \mathrm{N} 116^{\circ} 26^{\prime} \mathrm{E}\right.$; elevation of $\left.40.1 \mathrm{~m}\right)$. The station is located in a semi-arid to sub-humid climate zone, with a mean annual sunshine duration of $2600 \mathrm{~h}$, a mean annual temperature of $12.1^{\circ} \mathrm{C}$, an annual accumulated temperature $\left(>10^{\circ} \mathrm{C}\right)$ of $4730^{\circ} \mathrm{C}$, a mean frost-free period of $185 \mathrm{~d}$, a mean annual precipitation of $540 \mathrm{~mm}$, and a mean annual evaporation from a free water surface of $1800 \mathrm{~mm}$. The area is dominated by sandy loam.

Xuenuo No.2 species is planted during the summer of 2008-2010. The seeding time, harvest time, entire development stage, and rainfall amount are listed in Table 1, while the irrigation schedule is shown in Table 2.

\subsection{Measurements}

(i) Photosynthesis, transpiration, and stomatal conductance at the leaf scale. During the maize development stage in 
Table 1 Seeding time, harvest time, entire development stage, and rainfall amount

\begin{tabular}{ccccc}
\hline Year & Seeding time & Harvest time & Development state $(\mathrm{d})$ & Rainfall during the development stage $(\mathrm{mm})$ \\
\hline 2008 & June 25 & October 6 & 104 & 307.2 \\
2009 & June 16 & October 2 & 109 & 344.8 \\
2010 & June 25 & October 6 & 104 & 258.8 \\
\hline
\end{tabular}

Table 2 Irrigation schedule during the entire development stage of summer maize (including pre-sowing irrigation)

\begin{tabular}{|c|c|c|c|c|c|}
\hline Year & Irrigation date & Irrigation quantity (mm) & Year & Irrigation date & Irrigation quantity (mm) \\
\hline \multirow[t]{3}{*}{2008} & June 22 & 45 & 2010 & June 23 & 30 \\
\hline & July 29 & 40 & & July 24 & 72 \\
\hline & September 4 & 40 & & August 11 & 70 \\
\hline 2009 & June 30 & 40 & & & \\
\hline
\end{tabular}

2008-2009, the diurnal variations in leaf photosynthesis $\left(A_{-L}\right)$, transpiration $\left(T_{-L}\right)$, stomatal conductance $\left(g_{s w-L}\right)$, photosynthetically active radiation (PAR), temperature, and humidity were measured every 10-15 d using Li-6400 (Li-COR, USA). Five and six measurements were made in 2008 and 2009, respectively. Hourly readings were taken from 08:00 to 16:00. For each measurement, eight representatives of maize plants were randomly selected, wherein three functional leaves (one each from the top, middle, and bottom) were selected for measurement. The measurement point was the center of the leaves, which were held constantly perpendicular to the sunshine during measurement. A total of 24 leaves were used in each operation to measure $A_{-L}, T_{-L}, g_{s w-L}$, and other relevant environmental factors.

In 2010, the diurnal variations in the $A_{-L}, T_{-L}$, and $g_{s w-L}$ of the leaves in their natural state, as well as temperature and humidity, were measured on five occasions, each continued from 08:00 to 16:00 with $2 \mathrm{~h}$ intervals. During each measurement, two representatives of maize plants were randomly selected, wherein six functional leaves (two each from the top, middle, and bottom) were selected. The measurement point was the center of the leaves. A total of 12 representative leaves in their natural state were measured for their $A_{-L}, T_{-L}$, and $g_{s w-L}$, and other relevant environmental factors.

(ii) Photosynthesis and evapotranspiration at the canopy scale. Canopy-scale photosynthesis and evapotranspiration rates were measured using the eddy covariance system (Campbell Scientific Inc., USA):

$$
\begin{gathered}
F_{-C}=\frac{10^{6}}{44} \overline{w^{\prime} \rho_{c}^{\prime}}, \\
\lambda E T_{-C}=\lambda \rho_{a} \overline{w^{\prime} q^{\prime}},
\end{gathered}
$$

where $F_{-C}$ is the canopy $\mathrm{CO}_{2}$ flux, $\mu \mathrm{mol} \mathrm{m} \mathrm{m}^{-2} \mathrm{~s}^{-1} ; \lambda E T_{-C}$ is the latent heat flux, $\mathrm{W} \mathrm{m}{ }^{-2} ; \rho_{a}$ is the air density, $\mathrm{kg} \mathrm{m}^{-3} ; w^{\prime}$ is the pulsating quantity of vertical wind speed, $\mathrm{m} \mathrm{s}^{-1} ; \rho_{c}{ }^{\prime}$ is the $\mathrm{CO}_{2}$ density, $\mathrm{g} \mathrm{m}^{-3} ; q^{\prime}$ is the pulsating quantity of vapor density, $\mathrm{g} \mathrm{m}^{-3}$; and $10^{6} / 44$ is the conversion factor of unit.
The eddy covariance system used in the present study consists of a 3D sonic anemometer/thermometer (model CSAT3), a $\mathrm{CO}_{2} / \mathrm{H}_{2} \mathrm{O}$ open-circuit gas analyzer (model LI7500), a temperature and humidity sensor (model HMP45C), a net radiometer (model NR01), two heat flux plates (model HFP01), and a CR5000 data collector (Campbell Scientific Inc., USA). The 3D sonic anemometer/thermometer and the $\mathrm{CO}_{2} / \mathrm{H}_{2} \mathrm{O}$ open-circuit gas analyzer were used to measure the vertical fluctuations of wind and the $\mathrm{CO}_{2} / \mathrm{H}_{2} \mathrm{O}$ density at $0.1 \mathrm{~s}$ intervals, respectively. These sensors were mounted at $3.1 \mathrm{~m}$ above the ground. The net radiometer mounted at $4 \mathrm{~m}$ above the ground was used to measure the mean net radiation for 30 min periods. The ground heat flux $(G)$ was measured using soil heat flux plates installed at $20 \mathrm{~mm}$ depth below the soil, and data were averaged over $30 \mathrm{~min}$ periods. All sensors were connected to a data logger (model CR5000, Campbell Scientific Inc., Logan, UT, USA), and statistical analysis (average, variance, and covariance) was conducted for $30 \mathrm{~min}$ periods. Measurements were made from 2008 to 2010. During eddy covariance data processing, the outliers that were removed are described as follows: (1) data during precipitation period and $1 \mathrm{~h}$ before and after precipitation; (2) data apparently exceeding the physical meaning; and (3) data measured when the sensor was malfunctioning. Moreover, the Bowen ratio was computed to correct the latent heat flux, which was used to remove errors due to energy miscalculation [39].

(iii) Virtual leaf stomatal conductance at the canopy scale. Using the eddy covariance method to measure the canopy-scale latent heat flux, the P-M formula was used to derive reversely the virtual leaf stomatal conductance $g_{s w-C}$ at the canopy scale:

$$
\begin{aligned}
g_{s w-C}= & \frac{100}{2.24} \\
& \times\left[\frac{\gamma \cdot \lambda E T_{-C} \cdot\left(2.24 / 100 \cdot g_{a-C}\right)}{\Delta\left(R_{n}-G\right)+\rho_{a} C_{p} \mathrm{VPD} \cdot g_{a-C}-(\Delta+\gamma) \cdot \lambda E T_{-C}}\right] \\
& -g_{b w-C},
\end{aligned}
$$


where $R_{n}$ is the net radiation, $\mathrm{W} \mathrm{m}^{-2}$; $G$ is the soil heat flux, $\mathrm{W} \mathrm{m}{ }^{-2}$; VPD is the saturation deficit, $\mathrm{kPa} ; \gamma$ is the hygrograph constant, $\mathrm{kPa}{ }^{\circ} \mathrm{C}^{-1} ; \Delta$ is the slope of saturated vapressure specific heat of air, $\mathrm{J} \mathrm{kg}^{-1} \mathrm{~K}^{-1}$.

(iv) Other parameters. The LAI was measured once every $5 \mathrm{~d}$, and 51 representative plants were selected each time. The length and width of their leaves were measured, and the leaf area of each maize plant was calculated, then the LAI could be derived according to the planting density. SunScan canopy analysis system (Dynamax, Inc., USA). Measurements were made every $5 \mathrm{~d}$, with each measurement consisting of 45 measurement points. The PAR was measured continuously from 10:00 to 12:00 at the top and bottom of the canopy, and the mean values were calculated. The coefficient of extinction was computed from the measured LAI [40].

Canopy temperature was measured using a portable IR thermometer. Each measurement consisted of 120 randomly por-temperature curve, $\mathrm{kPa}{ }^{\circ} \mathrm{C}^{-1}$; and $C_{p}$ is the constant

The coefficient of extinction $\varepsilon$ was measured using the

selected measurement points, and their mean value was used as the canopy temperature.

Meteorological factors such as precipitation, humidity, and wind speed were measured using an automatic weather station (Monitor Sensors, Australia). A set of meteorological data was recorded automatically every $30 \mathrm{~min}$.

\section{Results and discussion}

\subsection{Diurnal variation of photosynthesis and transpira- tion at the leaf and canopy scales}

Figure 1 shows the diurnal variation of the photosynthesis, transpiration, and PAR of summer maize leaves in their natural state at different canopy heights on two typical days in 2010 (August 5 and 15; the plant height was 1.1 and 1.8 $\mathrm{m}$, respectively, and the LAI was 2.5 and 3.7, respectively). As shown in Figure 1, $A_{-L}$ and $T_{-L}$ at different heights of the canopy increased and reached their peaks (at around 12:00) when the PAR increased, and then decreased when the PAR
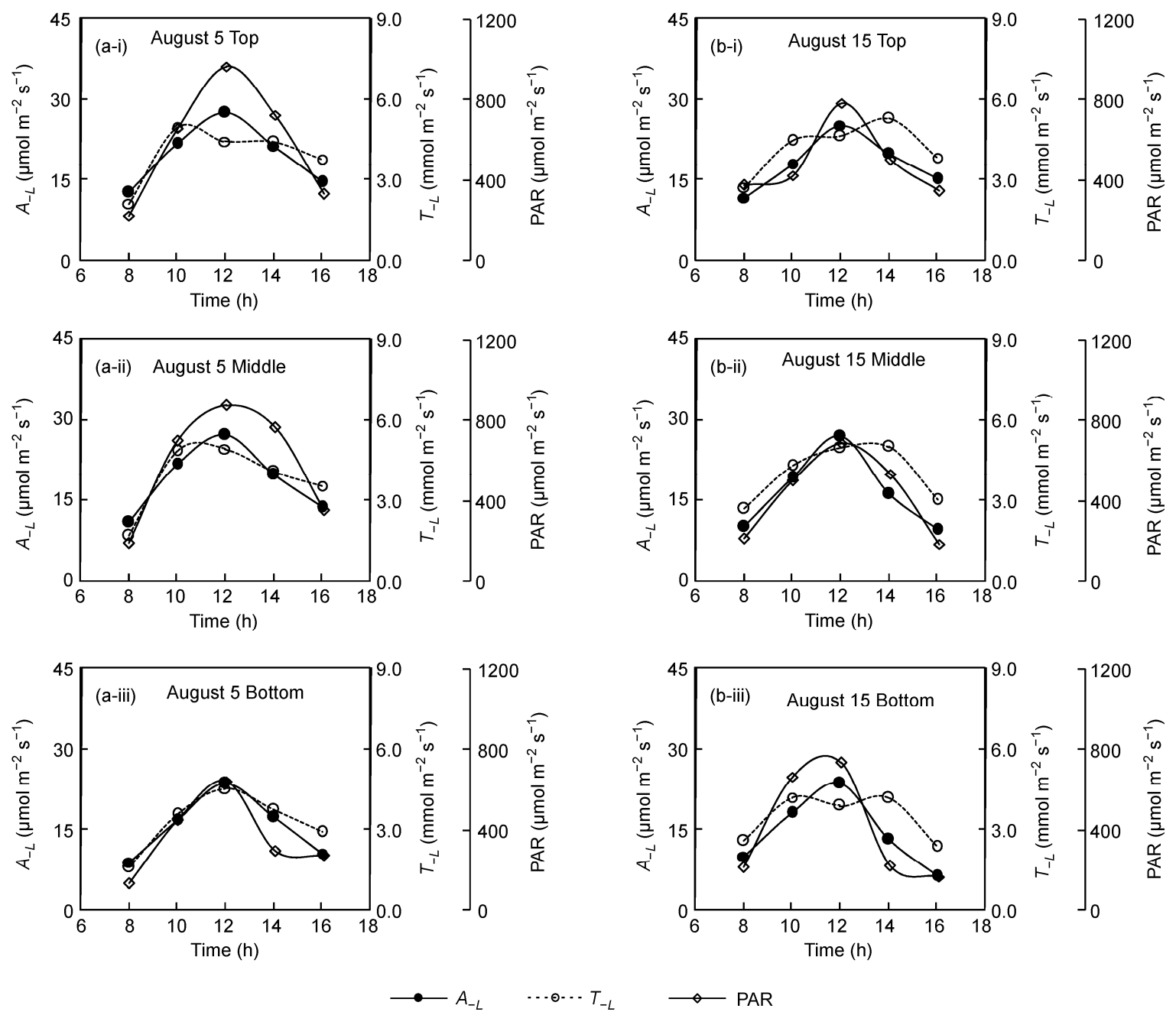

Figure 1 Diurnal variation of photosynthesis, transpiration, and PAR of leaves in their natural state at different canopy heights on typical days during the development stage of summer maize in 2010 . 
diminished. In addition, the photosynthesis and transpiration of leaves at the lower part of the canopy were less than those of leaves at the middle and upper parts of the canopy. This finding may be attributed to leaf age difference. Overall, the diurnal variation of the photosynthesis and transpiration of leaves at different heights of the canopy is consistent.

As shown in Figure 2, the diurnal variation of net photosynthesis rate and evapotranspiraton at the canopy scale is also substantially consistent. Furthermore, the photosynthesis rate differed less on these $2 \mathrm{~d}$, but their evapotranspiration greatly varied. This finding may be explained by the large difference in topsoil moisture content between these 2 $\mathrm{d}$ because of an irrigation made on August 11 and several precipitations recorded therein. On August 3, the root zone soil moisture accounted for $70 \%$ of field capacity moisture, and the average moisture of the top $10 \mathrm{~cm}$ soil accounted for $63 \%$ of field capacity moisture. On August 15, the root zone soil moisture accounted for $80 \%$ of field capacity moisture, and the moisture of the top $10 \mathrm{~cm}$ soil accounted for $85 \%$ of field capacity moisture.

\subsection{Analysis of the simulation results of the leaf-scale photosynthesis-transpiration coupling model}

The leaf-scale water-carbon coupling model was calibrated using the data measured on typical growth stage days (leaf photosynthesis measurement dates) of summer maize in 2008. This model was validated using the measurement data of 2009 and 2010 (Figures 3 and 4; Table 3). As shown in Figure 3 , the photosynthesis, transpiration, and WUE estimated by the model are substantially consistent with the diurnal variation trend of the measured values. As shown in Figure 4(a) and Table 3, when fitted to the measured data,
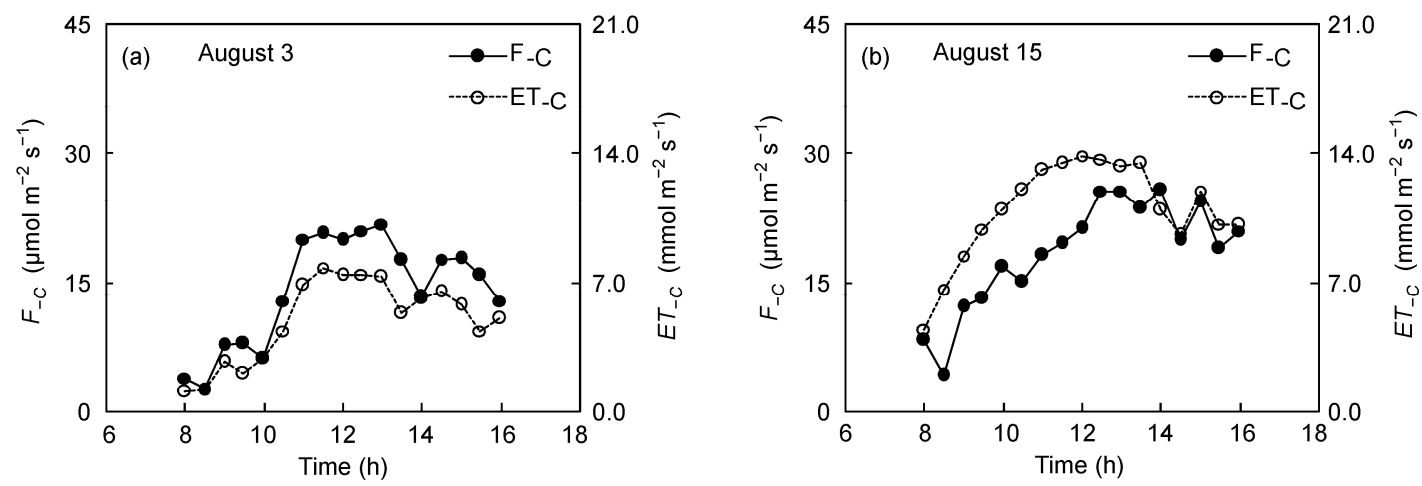

Figure 2 Diurnal variation of net photosynthetic rate and evapotranspiration at the canopy scale on typical days during the development stage of summer maize in 2010 .
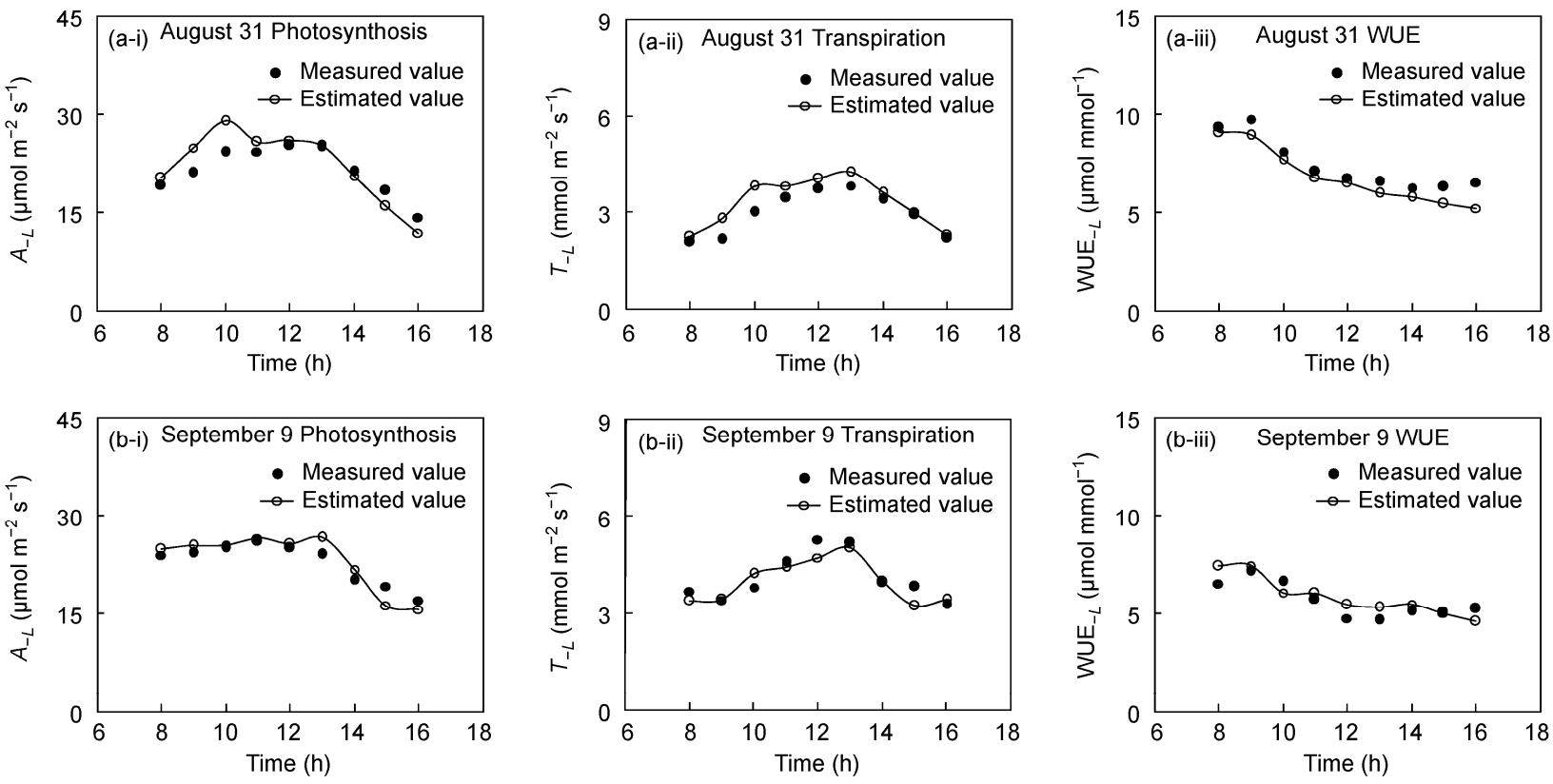

Figure 3 Diurnal variation of simulated and measured leaf photosynthesis, transpiration, and WUE values of summer maize during the development stage in 2009 . 
Table 3 Statistics of simulated and measured leaf-scale photosynthesis, transpiration, and WUE values of summer maize during the development stage in 2009 and $2010^{\text {a) }}$

\begin{tabular}{|c|c|c|c|c|c|c|c|}
\hline Model & $b$ & $R^{2}$ & $d_{I A}$ & RMSE & MAE & $\overline{O_{-L}}$ & $\overline{P_{-L}}$ \\
\hline Photosynthesis & 1.07 & 0.84 & 0.90 & $4.16 \mu \mathrm{mol} \mathrm{m}{ }^{-2} \mathrm{~s}^{-1}$ & $3.29 \mu \mathrm{mol} \mathrm{m}^{-2} \mathrm{~s}^{-1}$ & $22.46 \mu \mathrm{mol} \mathrm{m}^{-2} \mathrm{~s}^{-1}$ & $23.94 \mu \mathrm{mol} \mathrm{m}^{-2} \mathrm{~s}^{-1}$ \\
\hline Transpiration & 1.10 & 0.86 & 0.91 & $0.93 \mathrm{mmol} \mathrm{m}^{-2} \mathrm{~s}^{-1}$ & $0.71 \mathrm{mmol} \mathrm{m}^{-2} \mathrm{~s}^{-1}$ & $3.92 \mathrm{mmol} \mathrm{m}^{-2} \mathrm{~s}^{-1}$ & $4.35 \mathrm{mmol} \mathrm{m}^{-2} \mathrm{~s}^{-1}$ \\
\hline
\end{tabular}

a) $\overline{O_{-L}}$ is the mean of measured leaf-scale values; $\overline{P_{-L}}$ is the mean of simulated leaf-scale values of the model.

the leaf photosynthesis estimated by the model gives a regression coefficient $b$ of $1.07, R^{2}$ of $0.84, d_{I A}$ of 0.90 , RMSE of $4.16 \mu \mathrm{mol} \mathrm{m} \mathrm{m}^{-2} \mathrm{~s}^{-1}$, and MAE of $3.29 \mu \mathrm{mol} \mathrm{m} \mathrm{m}^{-2} \mathrm{~s}^{-1}$. The mean leaf photosynthesis estimated by the model and the measured value were $23.94 \mu \mathrm{mol} \mathrm{m} \mathrm{m}^{-2} \mathrm{~s}^{-1}$ and 22.46 $\mu \mathrm{mol} \mathrm{m} \mathrm{m}^{-2} \mathrm{~s}^{-1}$, respectively. These data indicate that the model fairly reflects the variation of the summer maize leaf photosynthesis in this region.

As shown in Figure 4(b) and Table 3, the model slightly overestimated the leaf transpiration when fitted to the measured data and provided $b$ of $1.10, R^{2}$ of $0.86, d_{I A}$ of 0.91 , RMSE of $0.93 \mathrm{mmol} \mathrm{m}^{-2} \mathrm{~s}^{-1}$, and MAE of 0.71 mmol m $\mathrm{m}^{-2} \mathrm{~s}^{-1}$. The leaf transpiration value estimated by the model and the measured value were $4.35 \mathrm{mmol} \mathrm{m}^{-2} \mathrm{~s}^{-1}$ and $3.92 \mathrm{mmol} \mathrm{m}^{-2} \mathrm{~s}^{-1}$, respectively. The model also performed well in estimating the WUE, yielding $b$ of $0.95, R^{2}$ of 0.74 , $d_{I A}$ of 0.88 , RMSE of $1.08 \mu \mathrm{mol} \mathrm{mmol}{ }^{-1}$, and MAE of 0.86

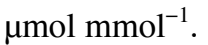

In summary, this leaf-scale water-carbon coupling model, SMPT-SB, reflects fairly the coupling relation between leaf photosynthesis and transpiration, and reasonably predicts the leaf WUE variation. $\mathrm{Yu}$ et al. verified the leaf-scale SMPT-SB using the measured data of maize and soybean. They found that this model could well simulate the photosynthesis, transpiration, and WUE without any environmental stress, which is in agreement with our results. However, the simulated values still show some errors with the measured values because the effects of leaf location and age on the plants were not considered. And the soil moisture and nutrient may affect the model prediction [34].

\subsection{Analysis of the simulation results of the canopy- scale photosynthesis-evapotranspiration coupling model}

The canopy water-carbon coupling model was calibrated using the data measured on typical growth stage days (photosynthesis measurement dates with a summer maize LAI greater than 3) of summer maize in 2008. This model was validated using the measurement data of 2009 and 2010 (Figure 5 and Table 4). As shown in Figure 5(a) and Table 4,
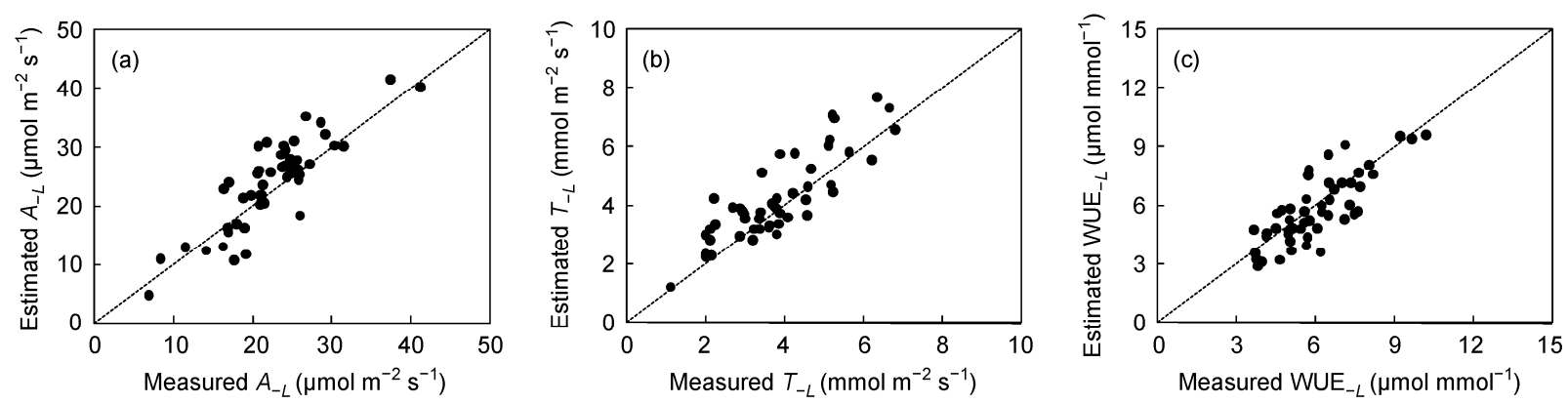

Figure 4 Comparison of simulated and measured leaf photosynthesis, transpiration, and WUE values of summer maize during the development stage in 2009 and 2010.
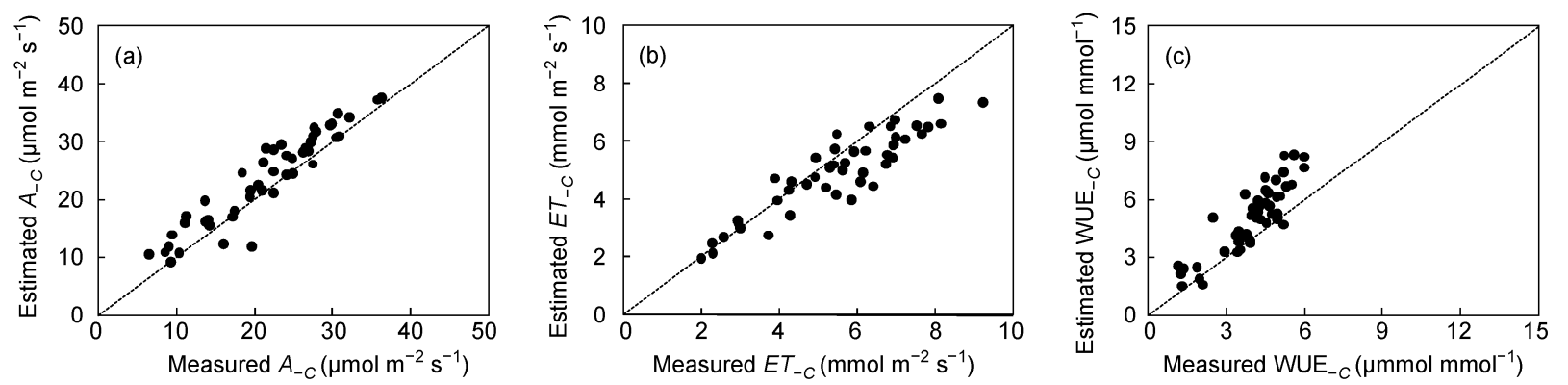

Figure 5 Comparison of simulated and measured canopy-scale photosynthesis, evapotranspiration, and WUE values of summer maize during the development stage in 2009 and 2010. 
Table 4 Statistics of simulated and measured canopy-scale photosynthesis, evapotranspiration, and WUE values of summer maize during the development stage in 2009 and $2010^{\text {a) }}$

\begin{tabular}{|c|c|c|c|c|c|c|c|}
\hline Model & $b$ & $R^{2}$ & $d_{I A}$ & RMSE & MAE & $\overline{O_{-C}}$ & $\overline{P_{-C}}$ \\
\hline Photosynthesis & 1.08 & 0.88 & 0.93 & $3.38 \mu \mathrm{mol} \mathrm{m}^{-2} \mathrm{~s}^{-1}$ & $2.70 \mu \mathrm{mol} \mathrm{m}{ }^{-2} \mathrm{~s}^{-1}$ & $21.52 \mu \mathrm{mol} \mathrm{m}{ }^{-2} \mathrm{~s}^{-1}$ & $23.49 \mu \mathrm{mol} \mathrm{m}^{-2} \mathrm{~s}^{-1}$ \\
\hline Evapotranspiration & 0.88 & 0.85 & 0.92 & $0.97 \mathrm{mmol} \mathrm{m}^{-2} \mathrm{~s}^{-1}$ & $0.77 \mathrm{mmol} \mathrm{m}^{-2} \mathrm{~s}^{-1}$ & $5.66 \mathrm{mmol} \mathrm{m}^{-2} \mathrm{~s}^{-1}$ & $5.04 \mathrm{mmol} \mathrm{m}^{-2} \mathrm{~s}^{-1}$ \\
\hline
\end{tabular}

a) $\overline{O_{-C}}$ is the mean of measured canopy-scale values; $\overline{P_{-C}}$ is the mean of simulated canopy-scale values of the model.

when fitted to the measured values, the canopy-scale photosynthesis estimates of the model yielded $b$ of $1.08, R^{2}$ of $0.88, d_{I A}$ of 0.93 , RMSE of $3.38 \mu \mathrm{mol} \mathrm{m}{ }^{-2} \mathrm{~s}^{-1}$, and MAE of $2.70 \mu \mathrm{mol} \mathrm{m} \mathrm{m}^{-2} \mathrm{~s}^{-1}$. The mean canopy-scale photosynthesis value estimated by this model and the measured value were $23.49 \mu \mathrm{mol} \mathrm{m} \mathrm{m}^{-2}$ and $21.52 \mu \mathrm{mol} \mathrm{m} \mathrm{s}^{-2} \mathrm{~s}^{-1}$, respectively. These data indicate that the model estimates fairly well the canopy-scale photosynthesis. Compared with the photosynthesis simulation, the simulation of canopy evapotranspiration has a slightly lower precision (Figure 5(b) and Table 4). The simulated canopy evapotranspiration and the measured values produced $b$ of $0.88, R^{2}$ of $0.85, d_{I A}$ of 0.92 , RMSE of $0.97 \mathrm{mmol} \mathrm{m}^{-2} \mathrm{~s}^{-1}$, and MAE of $0.77 \mathrm{mmol} \mathrm{m}^{-2} \mathrm{~s}^{-1}$. The mean canopy evapotranspiration value predicted by the model and the measured value were $5.04 \mathrm{mmol} \mathrm{m}^{-2} \mathrm{~s}^{-1}$ and $5.66 \mathrm{mmol} \mathrm{m}^{-2} \mathrm{~s}^{-1}$, respectively.

As shown in Figures 5(b), 6 and 7 and Table 4, the model underestimates evapotranspiration when the actual evapotranspiraion is large. This may be attributed to the fact that the single-layer model neglects soil evaporation, particularly when the topsoil contains large quantity of moisture (such as after a rain or irrigation). If soil evaporation ac- counts for a high proportion among the total evapotranspiration, the single-layer model's neglect for soil evaporation could reduce the precision of the canopy evapotranspiration simulation. Hence, the effect of soil moisture should be given emphasis in the further enhancement of the model. Ren et al. revealed that the percentage of soil evaporation in the total evapotranspiration greatly affects evapotranspiration simulation [35], which is consistent with our results. However, the photosynthesis rate at the canopy scale did not exhibit a significant difference despite the topsoil moisture difference because the root zone soil moisture was consistently large (data not given).

Based on Figure 5(c) and Table 4, the model overestimates the canopy-scale WUE because of the following main reasons. First, when the canopy evapotranspiration is less, a slight overestimation of photosynthesis or a slight underestimation of evapotranspiration results in a large overestimation of the WUE, an example of this is the WUE at 8:00 in Figure 6(a). Second, the model underestimates the canopy evapotranspiration but overestimates the photosynthesis, resulting in overestimated canopy WUE, an example is shown in Figure 6(b).
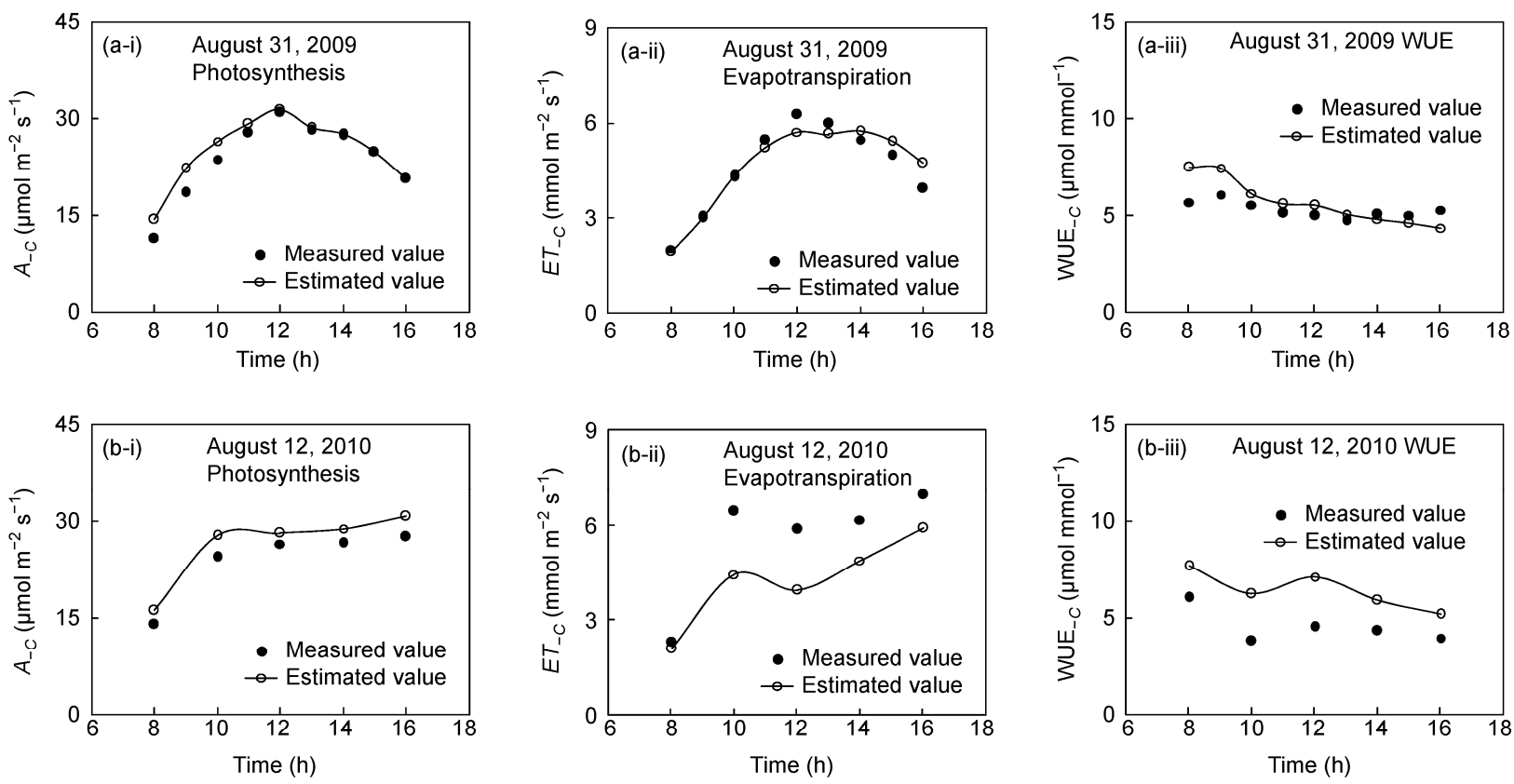

Figure 6 Diurnal variation of simulated and measured canopy-scale photosynthesis, evapotranspiration, and WUE values of summer maize during the development stage: topsoil moisture accounts for (a) $67 \%$ and (b) $90 \%$ of field capacity moisture. 

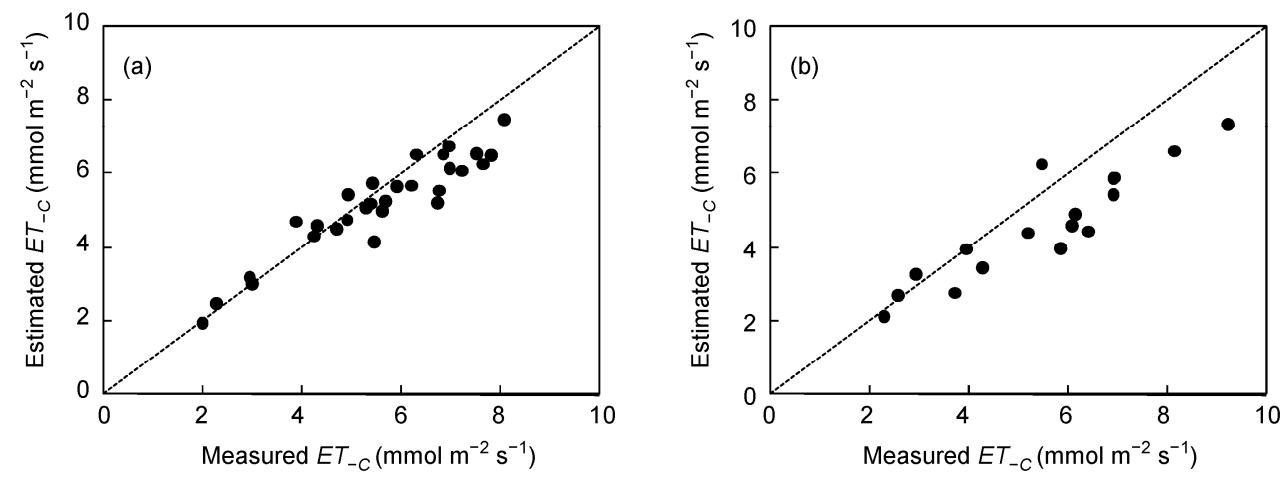

Figure 7 Comparison of simulated and measured canopy-scale evapotranspiration values with different topsoil moisture contents: topsoil moisture accounts for (a) less than $70 \%$ and (b) over $85 \%$ of field capacity moisture.
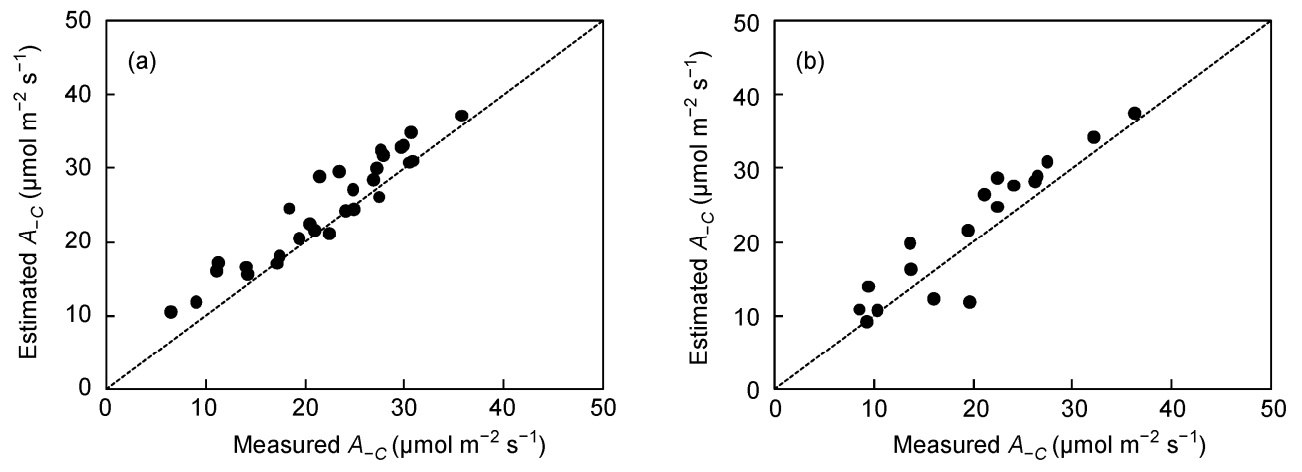

Figure 8 Comparison of simulated and measured canopy-scale photosynthesis values with different topsoil moisture contents: topsoil moisture accounts for (a) less than $70 \%$ and (b) over $85 \%$ of field capacity moisture.

\section{Conclusion}

The diurnal variations in the leaf and canopy photosynthesis and transpiration (or evapotranspiration) were systematically analyzed, and the SMPT-SB on these two scales were calibrated and validated. The major conclusions include the following:

(1) The diurnal variation of photosynthesis and transpiration (or evapotranspiration) is consistent at the leaf and canopy scales.

(2) The leaf photosynthesis, transpiration, and WUE estimated by the SMPT-SB are consistent with the measured values, fairly reflecting the SMPT-SB could well express the response of leaf photosynthesis, transpiration, and WUE to various environmental factors and the water-carbon coupling relationship.

(3) The SMPT-SB coupling model estimates the canopyscale photosynthesis and shows good agreement with the measured values. However, this model underestimates the evapotranspiration when the topsoil contains high amount of moisture and overestimates, to a certain extent, the WUE.

This work was supported by the National Natural Science Foundation of China (51009151, 51109225 and 91125017), the National Basic Research Program of China (2006CB403405) and the Special Scientific Fund sponsored by IWHR for Department of Irrigation and Drainage (1209).
1 Yu G R, Wen X F, Sun X M, et al. Overview of ChinaFLUX and evaluation of its eddy covariance measurement. Agric For Meteorol, 2006, 137: 125-137

2 Zhao F H, Yu G R. A review on the coupled carbon and water cycles in the terrestrial ecosystems (in Chinese). Prog Geogr, 2008, 27: 32-38

3 Monteith J L, Unsworth M H. Principles of Environmental Physics. London: Academic Press, 1990

4 Farahani H J, Bausch W C. Performance of evapotranspiration models for maize-bare soil to closed canopy. Trans ASAE, 1995, 38: 1049-1060

5 Shuttleworth W J, Wallace J S. Evaporation from sparse crops-An energy combination theory. Q J R Meteorolog Soc, 1985, 111: 839-855

6 Zhang B, Kang S, Li F, et al. Comparison of three evapotranspiration models to Bowen ratio-Energy balance method for a vineyard in an arid desert region of northwest China. Agric For Meteorol, 2008, 148: 1629-1640

7 Zhang B, Kang S, Zhang L, et al. An evapotranspiration model for sparsely vegetated canopies under partial root-zone irrigation. Agric For Meteorol, 2009, 149: 2007-2011

8 Farquhar G D, Von Caemmerer S. Modelling of Photosynthetic Response to Environmental Conditions. Berlin: Springer, 1982

9 Chen J M, Liu J, Cihlar J, et al. Daily canopy photosynthesis model through temporal and spatial scaling for remote sensing applications. Ecol Model, 1999, 124: 99-119

10 Luo Y, Medlyn B, Hui D, et al. Gross primary productivity in Duke Forest: Modeling synthesis of $\mathrm{CO}_{2}$ experiment and eddy-flux data. Ecol Appl, 2001, 11: 239-252

11 Pitman A J. The evolution of, and revolution in, land surface schemes designed for climate models. Int J Climatol, 2003, 23: 479-510

12 Sellers P J. Canopy reflectance, photosynthesis and transpiration. Int J Remote Sens, 1985, 6: 1335-1372 
13 Amthor J S. Scaling $\mathrm{CO}_{2}$-photosynthesis relationships from the leaf to the canopy. Photosynth Res, 1994, 39: 321-350

14 Wang Y P, Leuning R. A two-leaf model for canopy conductance, photosynthesis and partitioning of available energy I: Model description and comparison with a multi-layered model. Agric For Meteorol, 1998, 91: 89-111

15 Wang Y P, Jarvis P G. Description and validation of an array model -MAESTRO. Agric For Meteorol, 1990, 51: 257-280

16 Kosugi Y, Nakamura A, Tanaka $\mathrm{K}$, et al. Characteristics of $\mathrm{CO}_{2}$ and $\mathrm{H}_{2} \mathrm{O}$ fluxes of leaves of trees under different seasonal and soil moisture conditions in a buffer green zone. J Jpn Soc Reveget Tech, 1997, 22: $163-180$

17 Cowan I R, Farquhar G D. Stomatal function in relation to leaf metabolism and environment. Soc Exp Biol Symp, 1977, 31: 471-505

18 Leuning R. Modelling stomatal behaviour and and photosynthesis of eucalyptus grandis. Funct Plant Biol, 1990, 17: 159-175

19 Collatz G J, Ball J T, Grivet C, et al. Physiological and environmental regulation of stomatal conductance, photosynthesis and transpiration: A model that includes a laminar boundary layer. Agric For Meteorol, 1991, 54: 107-136

20 Ball J T. An Analysis of Stomatal Conductance. Stanford: Stanford University Press, 1988

21 Tang F D, Wu Y X, Han S J, et al. Relationship of stamatal conductance of leaf with environmental factors in broadleaved Korean pine forest at Changbai Mountain (in Chinese). Acta Ecol Sin, 2008, 28: 5649-5655

22 Leuning R. A critical appraisal of a combined stomatal-photosynthesis model for C3 plants. Plant Cell Environ, 1995, 18: 339-355

23 Sellers P J, Randall D A, Collatz G J, et al. A revised land surface parameterization $\left(\mathrm{SiB}_{2}\right)$ for atmospheric GCMs. Part I: Model formulation. J Clim, 1996, 9: 676-705

24 Hatton T J, Walker J, Dawes W R, et al. Simulations of hydroecological responses to elevated $\mathrm{CO}_{2}$ at the catchment scale. Aust J Bot, 1992, 40: 679-696

25 Yu Q, Wang T Z. Study on the coupling model of photosynthesis-transpiration-stomatal conductance and the $\mathrm{C} 3$ plant leaves physiological response to environmental factors (in Chinese). J Integr Plant Biol, 1998, 40: 740-754

26 Running S W, Coughlan J C. A general model of forest ecosystem processes for regional applications I. Hydrologic balance, canopy gas exchange and primary production processes. Ecol Model, 1988, 42: 125-154

27 Ji J. A climate-vegetation interaction model: Simulating physical and biological processes at the surface. J Biogeogr, 1995, 22: 445-451

28 Sellers P J, Los S O, Tucker C J, et al. A revised land surface parameterization ( $\mathrm{SiB} 2$ ) for atmospheric GCMs. Part II: The generation of global fields of terrestrial biophysical parameters from satellite data. J Clim, 1996, 9: 706-737

29 Foley J A, Prentice I C, Ramankutty N, et al. An integrated biosphere model of land surface processes, terrestrial carbon balance, and vegetation dynamics. Global Biogeochem Cycles, 1996, 10: 603-628

30 Liu J, Chen J M, Cihlar J, et al. A process-based boreal ecosystem productivity simulator using remote sensing inputs. Remote Sens Environ, 1997, 62: 158-175

31 Wang Q F, Niu D, Yu G R, et al. The simulation study on $\mathrm{CO}_{2}$ and energy fluxes of forest ecosystems in Changbai Mountain (in Chinese). Sci China Ser D: Earth Sci, 2004, 34(S2): 131-140

32 Yu G R, Kobayashi T, Zhuang J, et al. A coupled model of photosynthesis-transpiration based on the stomatal behavior for maize (Zea mays L.) grown in the field. Plant Soil, 2003, 249: 401-415

33 Yu G R, Zhuang J, Yu Z L. An attempt to establish a synthetic model of photosynthesis-transpiration based on stomatal behavior for maize and soybean plants grown in field. J Plant Physiol, 2001, 158: 861874

34 Yu G R, Wang Q F, Zhuang J. Modeling the water use efficiency of soybean and maize plants under environmental stresses: Application of a synthetic model of photosynthesis-transpiration based on stomatal behavior. J Plant Physiol, 2004, 161: 303-318

35 Ren C Y, Yu G R, Wang Q F, et al. Study on the coupling model of canopy water-carbon in terrestrial ecosystem (in Chinese). Sci China Ser D: Earth Sci, 2004, 34(S2): 141-151

36 Yu G R, Wang Q F, Yu Z L. Study on the coupling cycle of water carbon and process management in terrestrial ecosystem (in Chinese). Adv Earth Sci, 2004, 19: 831-838

37 Leuning R, Kelliher F M, Pury D G G, et al. Leaf nitrogen, photosynthesis, conductance and transpiration: Scaling from leaves to canopies. Plant Cell Environ, 1995, 18: 1183-1200

38 Popova Z, Pereira L S. Modelling for maize irrigation scheduling using long term experimental data from Plovdiv region, Bulgaria. Agric Water Manage, 2011, 98: 675-683

39 Guo J X, Mei X R, Lu Z G, et al. Field evapotranspiration measurement based on eddy covariance technology (in Chinese). Sci Agric Sin, 2004, 37: 1172-1176

40 Qi H Y, Zhou G S, Xu Z Z. Vertical distribution characteristics of photosynthetically active radiation in maize canopy and its controlling factors (in Chinese). J Meteorol Environ, 2008, 24: 22-26

Open Access This article is distributed under the terms of the Creative Commons Attribution License which permits any use, distribution, and reproduction in any medium, provided the original author(s) and source are credited. 